\title{
Informing population-specific smoking policy development for college campuses: An observational study
}

\author{
Lyndsay Fitzgeorge ${ }^{1}$, Amelia Tritter ${ }^{1,2}$, Matthew J. Fagan'2, Taniya S. Nagpal ${ }^{2}$, Harry Prapavessis ${ }^{2}$
}

\begin{abstract}
INTRODUCTION In Canada, young adults have the highest smoking rates among all other population groups and specifically college students are at a higher risk. To implement effective policies that can prevent smoking and increase cessation, a populationspecific approach is recommended.

METHODS Smoking and non-smoking young adults enrolled in a college program were recruited. Participants who did not smoke were asked to complete questionnaires about their demographics, college experience and the college environment. Additionally, they completed The Perceived Stress Scale and The Center for Epidemiologic Studies - Depression Scale. Students who were current smokers completed the same questionnaires with the addition of one questionnaire about their smoking behaviors. Percentages, means and standard deviations were used to describe the variables of interest and a chi-squared analysis was performed, when possible, to test the difference in response frequency between smoking and nonsmoking participants.

RESULTS Differences were observed between smoking $(n=65)$ and non-smoking students $(n=214)$. Specifically, smokers were more likely to have a family member that smoked and to participate in binge drinking. Both groups indicated that they are unaware of campus smoking regulations; however smokers were more opposed to implementing smoke-free policies.

CONCLUSIONS College students are unaware of campus smoking regulations. The descriptive information and differences observed between smoking and non-smoking students in this study should be taken into consideration when developing future smoking regulations/policies on college campuses.
\end{abstract}

\section{INTRODUCTION}

Smoking cigarettes is the leading cause of preventable death around the world ${ }^{1}$. In Canada, young adults (20-24 years) report the highest smoking frequency compared to other age groups and have demonstrated the least decline towards cessation ${ }^{2}$. This trend may be due in part to the fact that the majority of prevention and smoking cessation efforts have been directed towards youth and older adults, while young adults have been overlooked in areas of research, practice and policy ${ }^{3-5}$.

Furthermore, young adults who are at an increased risk of smoking are students enrolled at Canadian colleges, specifically in trade and technical training programs. In Canada, colleges typically provide hands-on training tailored for specific careers (i.e. electrician, chef, fitness professional, carpenter) and predominantly include one- to two-year certificate or diploma programs ${ }^{6}$. Whereas most university programs are three to four years and include a Bachelor's degree that may be used for further education (i.e. Master's degree) and/or professional schools (i.e. medical schools ${ }^{6}$ ). Compared to traditional 4-year university students, college students demonstrate significantly higher cigarette smoking rates $\left(20.2 \%\right.$ vs $29.6 \%$, respectively $\left.{ }^{7}\right)$. This 
discrepancy may be attributed to several factors that have been linked to a higher risk of smoking. For example, the average college student tends to be older, of lower socio-economic status, and may be pursuing a blue-collar profession ${ }^{8-11}$. In Ontario, $34 \%$ of adults who work in trades and farming are identified as smokers, compared to $24 \%$ of sales workers and $20 \%$ of those in professional or managerial roles ${ }^{12}$. Furthermore, the workforce formally trained by Canadian colleges are at greater risk of exposure to secondhand smoke and other carcinogens ${ }^{9}$. Therefore, it is important to target smoking prevention and cessation interventions specifically towards young adults on college campuses.

In order to develop targeted interventions, it is first important to understand the population of interest, this includes young adults on Canadian college campuses who are smokers and non-smokers ${ }^{13}$. Chapman and colleagues ${ }^{13}$ found that when they compared smokers to non-smokers, smokers were more likely to report that they felt self-exempt from the potential harmful health effects associated with smoking. This implies that smokers and non-smokers have different perceptions and opinions on smoking related topics. With Canadian campuses being shared by smokers and non-smokers alike, policy changes should take the perceptions of both groups into account.

Therefore, the purpose of this study is to understand the young adult smoking and nonsmoking population in order to inform future development of smoking prevention and cessation programs and policies. To this end, the following information was collected and compared between smoking and non-smoking young adults on College campuses: 1) smoking behaviors; 2) demographics (personal and psychological variables); 3) smoking perceptions (e.g. smoking prevalence, campus policies); 4) personal experiences with smoking (e.g. peer pressure); and 5) current smoker behavior and attitude towards quitting.

\section{METHODS}

This study took place at Fanshawe College (15000 full-time students enrolled) in London, Ontario from May until August 2014. Students attending Fanshawe College from January 2014 or earlier were recruited to participate in the study. By this time students had the opportunity to become familiar with the campus environment and their coursework.

This study was approved by the Fanshawe College Research Ethics Board (REB; \#14-03-27$1)$. Fourteen classrooms were contacted to recruit participants for the study including: Advanced Care Paramedicine, Architecture Technology, Automotive Power, Broadcast Journalism, Business (Human Resources, Marketing), Culinary (Skills, Management), Integrated Land Planning, Interior Design, Plumbing Apprenticeship, Police Foundations, Practical Nursing, and Radio Broadcasting. A researcher provided information about the study at the beginning or towards the end of the class period. Participants received an information letter and written informed consent was obtained.

Consenting students were first asked to indicate whether they had smoked in the last 30 days. If they responded yes, they were asked to complete the following questionnaires (if they responded no, they were asked to complete items 1-5):

1. Demographic and background information (age, gender, marital status, ethnic group, religion, income, parent's education, smoking behavior of immediate family).

2. Personal experience in college (date of enrollment, living arrangements, and participation in college activities) and with peers (number of close friends who smoke, number of house-mates who smoke, friends in program who smoke, friends outside of program who smoke, feelings of peer pressure to smoke).

3. Questions about the college environment (awareness of smoking cessation messages at school, school policy on smoking, perception of enforcement of campus regulations and desire for a smoke-free campus).

4. The Perceived Stress Scale ${ }^{14}$ (PSS). The PSS is used to measure the degree to which participants view situations in their life as stressful by scoring fourteen items on a scale of $0-4$. For the purpose of this study four items were removed $(4,5,12$, 13). The final calculation was a score out of 40 (higher score indicating greater stress perceived).

5. The Center for Epidemiologic Studies Depression Scale15 (CES-D). The CES-D scale is a screening tool containing 20 items describing 
depressive symptoms. Participants are asked to rate each item depending on how often they experienced that symptom in the previous week (i.e. less than 1 day $=0 ; 1-2$ days $=1 ; 3-4$ days $=2 ; 5-7$ days $=3$ ) with questionnaire scores ranging $0-60$. An arbitrary cut-off of 16 is used to suggest depressive symptomology.

6. The Fagerström Test for Cigarette Dependence16 (FTCD). The FTCD measures the perception of cigarette dependence. The FTCD contains 6 items that are summed to yield a total score of 10 points. A 5-level categorization system was used ranging from very low to very high dependence. These classes were scored as very low (0-2), low (3-4), medium (5), high (6-7), and very high (8-10).

7. Smoking behavior (number of cigarettes smoked per day, smoking behaviors before college, smoking with alcohol, desire to quit smoking and likelihood of seeking smoking cessation resources).

\section{Data analysis}

SPSS version 22 was used to analyze the data. Percentages, means and standard deviations were used to describe the variables of interest. Chi-squared and ANOVAs were performed, when possible, to test the difference in responses between smokers and non-smokers.

\section{RESULTS}

\section{Smoking Prevalence}

Of the 279 college students surveyed, $23.3 \%(n=65)$ were smokers (i.e. smoked at least one cigarette in the past 30 days $)$ and $76.7 \%(n=214)$ were nonsmokers (i.e. did not smoke a cigarette in the past 30
Table 1. Smoking prevalence by academic program

\begin{tabular}{|c|c|c|c|c|}
\hline \multirow[b]{2}{*}{ Academic program } & \multicolumn{2}{|c|}{$\begin{array}{c}\text { Smoker } \\
(n-61)\end{array}$} & \multicolumn{2}{|c|}{$\begin{array}{l}\text { Von- } \\
\text { smoker } \\
\text { (n-209) }\end{array}$} \\
\hline & n & $\%$ & n & $\%$ \\
\hline Architectural technology & 7 & 33.3 & 14 & 66.7 \\
\hline Paramedics & 0 & 0.0 & 8 & 100.0 \\
\hline Automotive power & 7 & 15.9 & 37 & 84.1 \\
\hline Broadcasting (journalism and radio) & 3 & 42.9 & 4 & 57.1 \\
\hline Business & 10 & 50.0 & 10 & 50.0 \\
\hline Culinary (skills and management) & 7 & 25.0 & 21 & 75.0 \\
\hline Design (interior and exterior) & 5 & 17.9 & 23 & 82.1 \\
\hline Plumbing & 8 & 38.1 & 13 & 61.9 \\
\hline Police foundations & 8 & 23.5 & 26 & 76.5 \\
\hline Practical nursing & 9 & 14.5 & 53 & 85.5 \\
\hline
\end{tabular}

days). Sixty of the 65 smokers provided information pertaining to smoking frequency, 43 of which were classified as daily smokers (i.e. smoked everyday) and 17 as occasional smokers (i.e. smoked in the past 30 days, but not daily). Smoking prevalence was categorized by academic program (Table 1).

\section{Demographic characteristics and psychological profile of smokers and non-smokers}

Smoker and non-smoker demographic characteristics pertaining to current college lifestyle and psychological variables (e.g. stress and depression levels) are presented in Table 2 . There were more male smokers than male non-smokers $(\mathrm{p}<0.05)$. The smoking population were more likely to have smoked cigarettes before college than non-smokers who now do not smoke $(\mathrm{p}<0.05)$. Additionally, smokers were more likely to have an immediate family member that currently smoked than non-smokers $(\mathrm{p}<0.05)$.

Table 2. Smoker and non-smoker demographic and personal characteristics

\begin{tabular}{|c|c|c|c|c|c|c|}
\hline \multirow[b]{2}{*}{ Variable } & \multicolumn{3}{|c|}{ Smokers } & \multicolumn{3}{|c|}{ Von smokers } \\
\hline & n & $\%$ & $\mathbf{M}(\mathbf{S D})$ & n & $\%$ & V (SD) \\
\hline Age & 65 & & $25.0(6.4)$ & 214 & & $23.4(5.7)$ \\
\hline Male & 65 & $63.1^{*}$ & & 214 & $49.1^{*}$ & \\
\hline Religious & 65 & 47.7 & & 214 & 60.7 & \\
\hline Married or previously married & 64 & 9.4 & & 213 & 15.0 & \\
\hline Employed (part-time or full-time) & 65 & 52.3 & & 213 & 54.4 & \\
\hline University education (or more) & 64 & 14.1 & & 214 & 15.9 & \\
\hline Smoked cigarettes before college & 65 & $84.6^{*}$ & & 214 & $15.4^{*}$ & \\
\hline Immediate family member who smokes & 65 & $67.7^{*}$ & & 210 & $43.3^{*}$ & \\
\hline
\end{tabular}


Table 2. Continued

\begin{tabular}{|c|c|c|c|c|c|c|}
\hline \multirow[b]{2}{*}{ Variable } & \multicolumn{3}{|c|}{ Smokers } & \multicolumn{3}{|c|}{ Von-smokers } \\
\hline & n & $\%$ & V (SD) & n & $\%$ & V (SI) \\
\hline Current living situation & 64 & & & 208 & & \\
\hline Residence & & 7.8 & & & 6.3 & \\
\hline Off-campus with roommates & & 28.1 & & & 34.1 & \\
\hline Off-campus with family/partner & & 45.3 & & & 49.5 & \\
\hline Off-campus alone & & 18.8 & & & 10.1 & \\
\hline Drinking behavior & 65 & & & 212 & & \\
\hline Do not drink & & $1.5^{*}$ & & & $16.0^{*}$ & \\
\hline Drink (< 4 drinks/occasion) & & 26.2 & & & 37.3 & \\
\hline Binge drink ( $\geq 4$ drinks/occasion) & & $72.3^{*}$ & & & $46.7^{*}$ & \\
\hline International student & 65 & 7.7 & & 213 & 10.8 & \\
\hline Varsity athlete & 65 & 6.2 & & 213 & 8.5 & \\
\hline Perceived Stress Scale score & 53 & & $1.7(0.7)$ & 182 & & $1.8(0.7)$ \\
\hline Depression scale (CES-D) score & 46 & & $20.6(11.5)$ & 167 & & $20.8(10.4)$ \\
\hline
\end{tabular}

CES-D: Center of Epidemiologic Studies Depression. ${ }^{*} p<0.05$

Finally, current drinking behaviors differed between smokers and non-smokers with current smokers indicating that they are more likely to participate in binge drinking $(\mathrm{p}<0.05)$. With respect to the psychological profile, there was no evidence that smokers had significantly higher stress and depression levels than non-smokers.

\section{Smoker and non-smoker opinions about smoking on campus}

Smoker and non-smoker perceptions and experiences with smoking behavior on campus as well as opinions towards campus smoking policies are presented in Table 3. Results indicate that both smokers and non-smokers were unaware of campus regulations for smoking with no difference observed between the groups. Smokers were more opposed to having a smoke-free campus than non-smokers $(\mathrm{p}<0.05)$, and non-smokers indicated they had been bothered by smoking on campus more often than smokers $(\mathrm{p}<0.05)$.

\section{Smoking behavior and cessation attitudes of current smokers}

Variables concerning previous and current smoking behaviors are displayed in Table 4. Eighty per cent of the smokers surveyed indicated that their smoking behavior increases when consuming alcohol. Furthermore, $42 \%$ indicated that their smoking behaviors have stayed relatively the same
Table 3. Smoker and non-smoker opinions on smoking on campus

\begin{tabular}{|c|c|c|c|c|}
\hline \multirow[b]{2}{*}{ Variable } & \multicolumn{2}{|c|}{ Smokers } & \multicolumn{2}{|c|}{$\begin{array}{l}\text { Von } \\
\text { smokers }\end{array}$} \\
\hline & n & $\% s$ & n & $\% s$ \\
\hline $\begin{array}{l}\text { Perceived percentage of college } \\
\text { students that smoke }\end{array}$ & 64 & & 213 & \\
\hline $0-20 \%$ & & 6.3 & & 8.5 \\
\hline $21-40 \%$ & & 50.0 & & 37.1 \\
\hline $41-60 \%$ & & 28.1 & & 35.7 \\
\hline $61+\%$ & & 15.6 & & 18.8 \\
\hline Felt pressured to smoke in college & 64 & 20.3 & 213 & 11.3 \\
\hline $\begin{array}{l}\text { Been bothered by someone smoking on } \\
\text { campus }\end{array}$ & 64 & & 212 & \\
\hline Never & & $70.3^{*}$ & & $33.5^{*}$ \\
\hline Rare ( $\leq$ once/month) & & $20.3^{*}$ & & $32.5^{*}$ \\
\hline Sometimes ( $\leq$ once/week $>$ > once/month) & & $6.3^{*}$ & & $18.9^{*}$ \\
\hline Often (> once/week) & & $3.1^{*}$ & & $15.1^{*}$ \\
\hline $\begin{array}{l}\text { Aware of current smoking-on-campus } \\
\text { policies }\end{array}$ & 64 & 37.5 & 211 & 31.8 \\
\hline $\begin{array}{l}\text { Opinion on implementing a smoke-free } \\
\text { campus }\end{array}$ & 64 & & 211 & \\
\hline Support & & $15.6^{*}$ & & $43.1^{*}$ \\
\hline Oppose & & $53.1^{*}$ & & $14.7^{*}$ \\
\hline Neutral/do not care & & 31.3 & & 42.2 \\
\hline
\end{tabular}

since before they began their college program. The number of individuals that had used specific resources for previous quit attempts are presented in Table 5. No significant differences $(\mathrm{p}>0.05)$ were found in resources used. 
Table 4. Smoking behavior

\begin{tabular}{|c|c|c|c|}
\hline Variable & n & $\%$ & V (SD) \\
\hline $\begin{array}{l}\text { Number of days smoked cigarettes in } \\
\text { the past month }\end{array}$ & 57 & & $22.0(10.6)$ \\
\hline $\begin{array}{l}\text { Average number of cigarettes smoked } \\
\text { per day }\end{array}$ & 49 & & $9.1(7.4)$ \\
\hline $\begin{array}{l}\text { Fagerström Test for Cigarette } \\
\text { Dependence score }\end{array}$ & 48 & & $3.7(1.2)$ \\
\hline Smoking behavior since entering college & 57 & & \\
\hline Increased & & 29.8 & \\
\hline Decreased & & 21.1 & \\
\hline Stayed the same & & 42.1 & \\
\hline Did not smoke before college & & 7.0 & \\
\hline $\begin{array}{l}\text { Smoking behavior while drinking } \\
\text { alcohol }\end{array}$ & 55 & & \\
\hline Increases & & 80.0 & \\
\hline Decreases & & 3.6 & \\
\hline Stays the same & & 12.7 & \\
\hline Do not drink alcohol & & 3.6 & \\
\hline
\end{tabular}

Table 5. Resources previously used for smoking cessation (n=65)

\begin{tabular}{ll} 
Smoking cessation resource & $\%$, SD \\
\hline Free phone counselling & $1.1,0.3$ \\
Group or school counselling & $1.2,0.5$ \\
Community programs & $1.1,0.4$ \\
Online resources & 1.6 .1 .1 \\
Online chat rooms & $1.1,0.4$ \\
Medication & $2.0,1.3$ \\
Herbal products & $1.8,1.3$ \\
Hypnosis & $1.6,1.2$ \\
One-on-one counselling & $1.4,1$ \\
Quit without support & $4.2,1.3$
\end{tabular}

\section{DISCUSSION}

The current study examined the descriptive differences between smokers and non-smokers on a Canadian college campus to inform development of future smoking prevention and cessation programs/ policies. The overall findings indicated significant differences among smokers and non-smokers related to: drinking behavior, sex, parental smoking status, opinions on smoker-free policies and awareness of campus policies. Further discussions on the major findings, strengths and limitations of the current study are given later.

\section{Predictors of smoking behaviour}

The current smoking population that was surveyed ( $\mathrm{n}$
=65) smoked on average 9.1 cigarettes per day and had a mean score of 3.7 (1.2) on the Fagerström Test for Cigarette Dependence. Approximately 30\% of the smokers had increased their smoking behavior since entering college, which is not consistent with the literature as a recent systematic review found cigarette smokers in college typically start smoking in college and do not enter college as smokers ${ }^{17}$. Furthermore, $80 \%$ of smokers stated that they increased their smoking frequency while drinking, and as college students are drinking at a higher prevalence and are more likely to binge drink more frequently than the adult population this finding warrants further examination $^{15}$. Perhaps future program development for smoking cessation and prevention should consider including alcohol prevention/reduction information in conjunction with smoking. Furthermore, research has shown that environments that promote drinking often trigger cigarette use and this is consistent with our findings ${ }^{18}$. This potentially provides targeted locations for implementation of smoking cessation/ prevention interventions or messaging for young adults.

Certain behavioral and environmental individual descriptors have been shown to predict smoking behavior ${ }^{19}$. These include high levels of alcohol consumption, parents who smoke, and less leisure time physical activity ${ }^{20}$. First, the study provided results that college students who smoke also show a greater consumption of alcohol than their non-smoking counterparts, this finding has been supported in the literature, as also seen in the adult population ${ }^{21}$. A recent review by Adams ${ }^{22}$ found two main mechanistic pathways for the co-morbidities of cross-reinforcement via the dopamine pathway and cross-tolerance from shared nicotinic acetylcholine receptor ( $\mathrm{nAChR}$ ) utilization but further research is warranted.

Having an immediate family member who smokes or being male has also been linked to higher prevalence of smoking in the adult population ${ }^{20}$. The current study supports this finding in the college population as $67.7 \%$ of the smokers had an immediate family member who smoked, in comparison to $43.3 \%$ of non-smokers $(p<0.05)$. Furthermore, $63 \%$ of the smokers were male whereas only $49 \%$ of the nonsmoking population identified as males $(\mathrm{p}<0.05)$. This finding suggests that perhaps a family-based approach would be effective in reducing cigarette 
use. Furthermore, future programming should account for the sex differences observed in the current study and in previous literature for the general population.

A few demographic and personal characteristics were not found to be significantly different between the smokers and non-smokers. For example: married or previously married, employment status, education level, current living situation, international student status, and varsity athlete status were not different between the groups. In contrast to Hansen and Chen ${ }^{20}$, being a varsity athlete did not change the likelihood of smoking in this population. A possible reason for this finding could be the small number of varsity athletes surveyed; with only 4 smokers $(6.2 \%)$ and 18 nonsmokers $(8.5 \%)$ identifying as varsity athletes.

In the current study, there was no difference in smoking prevalence among international and non-international students. This finding is not in accordance with the literature with respect to the prevalence of smoking in different countries ${ }^{23}$. For example, $\mathrm{Ng}$ et al. ${ }^{23}$ found China, Greece, Ireland, Italy, Japan, Kuwait, Korea, the Philippines, Uruguay, Switzerland and Russia to have a larger proportion of the population smoking than Canada. The survey, however, did not ask where international students are from and therefore this cannot be further explored with the current sample.

Finally, living in residence or off campus did not significantly differ between the smokers $(7.8 \%$ in residence) and non-smokers ( $6.3 \%$ in residence). Based on our findings, the residence setting should be further explored to ensure that campus policies regarding smoking can effectively be implemented in student on-campus living space as well.

\section{Smokers readiness to quit}

This study examined the smoking populations readiness to quit and found that $61.1 \%$ of the students were intending to quit before graduation and $69.8 \%$ previously tried to quit smoking. This is in accordance with the literature where every six months $2 / 3$ of smokers consider a quit attempt ${ }^{24}$. Within many of the widely used theoretical frameworks for behavior change, the individual's intentions and motivations play a key role in the uptake or cessation of a behavior ${ }^{25,26}$. Specifically, the Health Action Process Approach (HAPA) applies to overcoming health-compromising behaviors such as smoking, and outlines the importance of understanding an individual's intentions ${ }^{25}$. Hence, interventions using a theoretical framework (like HAPA) based upon the populations intentions could be successful in the college population considered in this study.

The likelihood of using resources to quit smoking was also examined. In accordance with work done in the adult population, the likelihood of using resources in general is not high ${ }^{27-29}$. The results from the current study show that the likelihood of using (scale 1-5) quit smoking resources is low. These findings suggest that many smokers will struggle with cessation, as a clinical review on the effectiveness of smoking cessation interventions revealed that quitting on your own is the least effective cessation method ${ }^{30}$. By understanding the differences between smokers and non-smokers, population specific resource development and promotions can be implemented.

\section{Campus policy}

In Canada, smoking is not permitted within ten meters of a public building ${ }^{31}$. This is nationally regulated and any violators are subject to being fined $^{31}$. In addition to this law, Canadian universities and colleges may have other regulations for where smoking is or is not permitted on campus but these regulations differ between schools. With no National guidelines in place for tobacco control on campus settings it was important to gauge the opinions of a smoke-free campus from current students. The opinions of a smoke-free campus were significantly different $(\mathrm{p}<0.05)$ between the smokers and nonsmokers, with $53.1 \%$ of smokers opposing the implementation of a smoke-free campus and only $14.7 \%$ of non-smokers opposing. These results suggest that students who currently smoke are largely not in favor of a smoke-free campus and this may have implications for policies. An effective way may be to consider smoke-free zones (areas where smoking is not permitted) or smoking zones (designated areas where smoking is permitted), however research is needed on which strategy would be most effective in terms of adherence. Implementing these zones may be helpful and may satisfy both groups as $70 \%$ of the non-smokers included in this study indicated that smoking bothered them once per week and a majority of the smokers indicated they are not in favour of a 
smoke-free campus. Furthermore, it was found that greater than half of the smokers $(62.5 \%)$ and nonsmokers $(68.2 \%)$ were not aware of current smokingon-campus policies. This potentially suggests that non-smokers may be bothered by smoking on campus because students are unaware of where they can or cannot smoke. This also suggests that the current regulations in place for smoking on campus are not effective. Future campus policy should strive to ensure effective strategies are in place to educate smokers and non-smokers about the regulations.

\section{Strengths and limitations}

Several strengths have been identified within the study. First, this is the first study to examine the Canadian college population only, in regards to population-specific demographics and opinions on smoking related topics. This can be used for informing the development of smoking policies on Canadian college campuses. Second, the population of smoking (23\%) and non-smoking young adults (77\%) is in accordance with the smoking prevalence found in Canada. Therefore, our sample is representative of the prevalence of young adults who are current smokers in Canada.

The current study is not without limitations and should be discussed. First, this study used a convenience sample, therefore a sample size calculation was not done prior to data collection. Second, the findings cannot be generalized to all Canadian college campuses as only one college campus was surveyed. Furthermore, post-secondary education systems may vary across countries. Future research can add to the current data by completing an a priori sample size calculation to have a greater number of participants and include a more diverse population by recruiting students from across Canadian college campuses and in other countries.

\section{CONCLUSIONS}

These results highlight the differences between smokers and non-smokers on a Canadian college campus. When compared to non-smokers, the surveyed college students who smoked were more likely to be male, have an immediate family member who smoked and have a higher prevalence of binge drinking/cigarette use when consuming alcohol. Furthermore, college students who smoke are not in favor of smoke-free campuses, and both smokers and non-smokers are unaware of campus smoking regulations. These findings should be taken into consideration to develop population specific smoking prevention and cessation programs and policies on Canadian college campuses. Furthermore, this data should be expanded by including a larger more diverse sample of young adults across Canadian college campuses and other countries.

\section{Implications}

Practice: The demographic information and opinions on current smoking policies from smoking and non-smoking young adults currently enrolled in a Canadian college program provides information to assist with the development of population-specific college campus smoking policies and regulations.

Policy: Policymakers should consider the differences between smoking and non-smoking college students when designing and implementing smoking regulations on college campuses to ensure that the policy is for a specific population as this may increase. Research: Future research can add to the existing data by including a larger more diverse sample from many Canadian college campuses and other countries, as this can increase the generalizability of the results and potentially lead to additional observed differences between smoking and non-smoking students.

\section{REFERENCES}

1. World Health Organization (WHO). WHO Report on the Global Tobacco Epidemic. Vol 5.; 2013. doi:10.1002/aehe.3640230702

2. Government of Canada. Canadian Tobacco Use Monitoring Survey. Smoking in Canada: an overview. https://www.canada.ca/en/health-canada/services/ publications/healthy-living/canadian-tobacco-usemonitoring-survey-ctums-2012.html. Published 2012.

3. Backinger CL, Fagan P, Matthews E, Grana R. Adolescent and young adult tobacco prevention and cessation: current status and future directions. Tob Control. 2003;12 Suppl 4:IV46-V53. doi:10.1136/tc.12.suppl.

4. Hammond D. Smoking behaviour among young adults: Beyond youth prevention. Tob Control. 2005;14(3):181185. doi:10.1136/tc.2004.009621

5. Green MP, McCausland KL, Xiao H, Duke JC, Vallone DM, Healton CG. A closer look at smoking among young adults: Where tobacco control should focus its attention. Am J Public Health. 2007;97(8):1427-1433. doi:10.2105/AJPH.2006.103945

6. Boothby D, Drewes T. Education in Canada : 
Postsecondary Returns to University, Trades. Can Public Policy. 2006;32(1):1-21. doi:10.2307/3552240

7. Sanem JR, Berg CJ, An LC, Kirch MA, Lust KA. Differences in Tobacco Use Among Two-Year and Four-Year College Students in Minnesota. Journal of American College Health. 2008;58(2). doi:10.1080/07448480903221376

8. Loukas A, Murphy JL, Gottlieb NH. Cigarette smoking and cessation among trade or technical school students in Texas. J Am Coll Heal. 2008;56(4):401-407. doi:10.3200/JACH.56.44.401-408

9. Barbeau EM, Krieger N, Soobader MJ. Working Class Matters: Socioeconomic Disadvantage, Race/Ethnicity, Gender, and Smoking in NHIS 2000. Am J Public Health. 2004;94(2):269-278. doi:10.2105/AJPH.94.2.269

10. Sorensen G, Barbeau E, Hunt MK, Emmons K. Reducing Social Disparities in Tobacco Use: A Social-Contextual Model for Reducing Tobacco Use among Blue-Collar Workers. Am J Public Health. 2004;94(2):230-239 doi:10.2105/AJPH.94.2.230

11. Howard J. Smoking is an occupational hazard. Am J Ind Med. 2004;46(2):161-169. doi:10.1002/ajim.10364

12. Ontario Tobacco Research Unit (OTRU). Indicators of Smoke-Free Ontario Progress.; 2010.

13. Chapman S, Wai Leng Wong, Smith W. Self-exempting beliefs about smoking and health: Differences between smokers and ex-smokers. Am J Public Health. 1993;83(2):215-219. doi:10.2105/AJPH.83.2.215

14. Cohen S, Kamarck T, Mermelstein R. A Global Measure of Perceived Stress. J Health Soc Behav. 1983;24(4):385396. doi:10.2307/2136404

15. Radloff LS. A self-report depression scale for research in the general population. Appl Psychol Meas. 1977;1(3):385-401.doi:10.1177/014662167700100306

16. Fagerström K. Determinants of tobacco use and renaming the FTND to the Fagerström test for cigarette dependence. Nicotine Tob Res. 2012;14(1):75-78. doi:10.1093/ntr/ntr137

17. Freedman KS, Nelson NM, Feldman LL. Smoking initiation among young adults in the United States and Canada, 1998-2010: a systematic review. Prev Chronic Dis. 2012;9(5):E05. doi:10.5888/pcd9.110037

18. Park CL, Levenson MR. Drinking to cope among college students: prevalence, problems and coping processes. J Stud Alcohol. 2002;63(4):486-497. doi: $10.15288 /$ jsa.2002.63.486

19. Matarazoo G, Saslow J. Psychological and related characteristics of smokers and nonsmokers. Psychol Bull. 1960;57(6):493-513. doi:10.1037/h0040828

20. Hanson MD, Chen E. Socioeconomic status and health behaviors in adolescence: A review of the literature. J Behav Med. 2007;30(3):263-285. doi:10.1007/s10865-007-9098-3

21. Ma J, Betts NM, Hampl JS. Clustering of lifestyle behaviors: The relationship between cigarette smoking, alcohol consumption, and dietary intake. Am J Heal Promot.
2000;15(2):107-117. doi:10.4278/0890-1171-15.2.107

22. Adams S. Psychopharmacology of Tobacco and Alcohol Comorbidity: a Review of Current Evidence. Curr Addict Reports. 2017;4(1):25-34. doi:10.1007/s40429-017-0129-z

23. Ng M, Freeman MK, Fleming TD, et al. Smoking prevalence and cigarette consumption in 187 countries, 1980-2012. JAMA - J Am Med Assoc. 2014;311(2):183192. doi:10.1001/jama.2013.284692

24. Reid J, Hammond D, Rynard V, Burkhalter R. Tobacco Use in Canada : Patterns and Trends. Can Cancer Soc. 2015:1-100. http://www.tobaccoreport.ca/2013/ TobaccoUseinCanada_2013.pdf. Accessed February 2018.

25. Schwarzer R, Luszczynska A. How to overcome health-compromising behaviors: The health action process approach. Eur Psychol. 2008;13(2):141-151. doi:10.1027/1016-9040.13.2.141

26. Deci EL, Ryan RM. Self-determination theory: A macrotheory of human motivation, development, and health. Can Psychol. 2008;49(3):182-185. doi:10.1037/a0012801

27. Fiore MC, Novotny TE, Pierce JP, Al E. Methods used to quit smoking in the united states: Do cessation programs help? JAMA. 1990;263(20):2760-2765. doi: 10.1001/jama.1990.03440200064024

28. Zhu SH, Melcer T, Sun J, Rosbrook B, Pierce JP. Smoking cessation with and without assistance: A populationbased analysis. Am J Prev Med. 2000;18(4):305-311. doi:10.1016/S0749-3797(00)00124-0

29. Shiffman S, Brockwell SE, Pillitteri JL, Gitchell JG. Use of Smoking-Cessation Treatments in the United States. Am J Prev Med. 2008;34(2):102-111. doi:10.1016/j.amepre.2007.09.033

30. Lancaster T, Stead L, Silagy C, Sowden A. Effectiveness of interventions to help people stop smoking: Findings from the Cochrane Library. Bmj. 2000;321(7257):355358. doi:10.1136/bmj.321.7257.355

31. Lemstra M, Neudorf C, Opondo J. Implications of a public smoking ban. Can J Public Heal Can Sante'e Publique. 2008;99(1):62-65.

\section{CONFLICTS OF INTEREST}

L. Fitzgeorge received a grant from Fanshawe College. Each of the authors has completed and submitted an ICMJE form for disclosure of potential conflicts of interest. The authors declare that they have no competing interests, financial or otherwise, related to the current work.

\section{FUNDING}

This study was supported by a Research Innovation Fund (RIF) grant from Fanshawe College (\#2015-03-RIF) awarded to L. Fitzgeorge.

PROVENANCE AND PEER REVIEW Not commissioned; externally peer reviewed. 